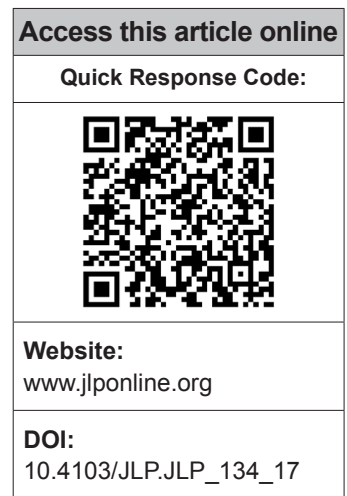

Department of Pathology, PSG Institute of Medical Sciences and Research, Coimbatore, Tamil Nadu, India

Address for correspondence: Dr. Umamaheswari Gurusamy,

Department of Pathology,

PSG Institute of

Medical Sciences and Research, Peelamedu, Coimbatore - 641004 ,

Tamil Nadu, India. E-mail: umsi2giri@gmail.

Submission: 24-08-2017 Accepted: 22-05-2018

\title{
Second-trimester fetal autopsy: A morphological study with prenatal USG correlations and clinical implications
}

\author{
Chaitra Venkataswamy, Umamaheswari Gurusamy, S. Vidhya Lakshmi
}

\section{Abstract:}

OBJECTIVES: The objective of this study is to analyze the second-trimester fetal autopsies and to reemphasize the role of autopsy by comparing autopsy findings with prenatal ultrasound observations.

MATERIALS AND METHODS: Retrospective analysis of second-trimester fetal autopsies over a period of 7.5 years (January 2009-June 2016). A standard protocol of autopsy procedure was followed, which included external examination with photography, X-ray, internal examination, and histopathological examination. In fetuses with congenital malformations (CMs), the findings of prenatal ultrasonogram and autopsy examination were compared.

RESULTS: We analyzed a total of 66 fetuses, which includes 17 intrauterine fetal death, 49 terminations for $\mathrm{CM}$, and increased risk for chromosomal abnormality. In fetuses with $\mathrm{CM}$, multiple anomalies were more common than a single anomaly. The most common anomalies were seen involving central nervous system (neural tube defect) followed by the genitourinary system. Autopsy confirmed prenatal ultrasound findings in all cases except three. Complete agreement between USG findings and autopsy were seen in 17 cases (39.7\%). Additional findings on autopsy were noted in 25 cases $(62.2 \%)$. Among these, 15 cases had a significant change of recurrence risk due to altered initial ultrasound diagnosis.

CONCLUSION: Fetal autopsy plays an important role in arriving at the final diagnosis and detecting the cause of death. This information is very essential for the clinicians, in genetic counseling of the parents, and management of future pregnancies.

Keywords:

Congenital malformations, fetal autopsy, multiple anomalies, prenatal ultrasound

\section{Introduction}

The common indications for L second-trimester fetal autopsies are termination of pregnancy (TOP) for congenital anomalies, intrauterine fetal death (IUFD), and inevitable abortion. ${ }^{[1]}$ TOP for congenital anomalies accounts for the majority of cases of second-trimester fetal autopsies as most of the anomalies are detected during 18-20 weeks of gestation by anomaly scan which is an integral part

This is an open access journal, and articles are distributed under the terms of the Creative Commons Attribution-NonCommercial-ShareAlike 4.0 License, which allows others to remix, tweak, and build upon the work non-commercially, as long as appropriate credit is given and the new creations are licensed under the identical terms.

For reprints contact: reprints@medknow.com of antenatal screening. These remain the common cause of perinatal deaths both in developed and developing countries and account for $25 \%-30 \%$ and $10 \%-15 \%$, respectively. ${ }^{[2]}$ The occurrence of these anomalies in subsequent pregnancy varies from negligibly low to $25 \%$, and it depends on the etiology of diagnosis. Hence, it is important to make an accurate diagnosis.

In the present era, Ultrasonographic (USG) examination can accurately diagnose many lesions but has its own limitation in detecting soft-tissue lesions such as malrotation

How to cite this article: Venkataswamy C, Gurusamy U, Lakshmi SV. Second-trimester fetal autopsy: A morphological study with prenatal USG correlations and clinical implications. J Lab Physicians 2018;10:338-45. 
of intestines, asplenia/polysplenia, and pulmonary hypoplasia, and the success rates of ultrasound also depend on the equipment used and expertise of the sonologist. Perinatal autopsy either confirms or refute the ultrasound diagnosis and complements USG examination in making a precise diagnosis.

The objectives of the present study are to evaluate the reasons for second-trimester fetal autopsies, to categorize the congenital malformations (CMs) into various systems, syndromes, and complexes, and to compare the autopsy findings with prenatal USG examination.

\section{Materials and Methods}

The retrospective analysis of all second-trimester fetal autopsies from January 2009 to June 2016 (7.5 years) was done in the Department of Pathology. Fetuses with gestational age 14-28 weeks were included in the study. Fetuses with gestational age $<14$ weeks and $>28$ weeks were excluded from the study. Informed written consent for performing autopsy examination was obtained from either of the parents before the autopsy. All the fetuses were examined on preset protocol based on the recommendation given in guidelines in autopsy practice by Royal College Of the Pathologists, ${ }^{[3]}$ which included photography, fetogram (whole body radiography), and external and internal examination.

Evisceration is performed by starting with a linear skin incision extending from symphysis menti to midline of chest, abdomen, passing to the left side of the umbilicus, and extending up to the symphysis pubis. In situ assessment of the intestines was done to rule out malrotation and they were removed from jejunum up to the rectum. Rest of the organs was taken out as "en bloc" by freeing the tongue from the floor of the mouth and releasing the attachments of the neck structures. The pelvic organs were cut as low as possible. External genitalia and urethra were dissected in case of suspected urorectal septum malformation. The individual system was thoroughly inspected and dissected for anomalies.

The brain is removed by incising the scalp behind one ear extending to vertex and to the other ear. Skin flaps are reflected anteriorly up to the eyebrows and posteriorly up to the nape of the neck. Skull bones are opened along the suture lines. The brain is delivered by placing the head at a lower level than the body, by releasing the nerve attachments, and falx cerebri, tentorium cerebelli and the upper cervical spinal cord is incised. The removed brain is then fixed by hanging in formalin using gauze.

All the organs are weighed. Histopathological examination of the brain, thyroid, thymus, heart, lung, liver, pancreas, spleen, kidney, adrenal, gonads, and placenta was carried out. Additional sections from the skin, muscle, bladder, pylorus, etc., were also studied when required.

In cases of fetuses terminated for $\mathrm{CMs}$, the findings on autopsy and prenatal ultrasound examination were compared.

Approval was obtained from the institutional Ethical Clearance Committee.

\section{Results}

There were 87 fetal autopsies in 7.5 years of which 66 cases $(75.8 \%)$ were second-trimester fetuses. Causes of second-trimester fetal autopsies are summarized in Figure 1.

In cases of IUFD and abortions, mean maternal age was 27 years (range19-35) and mean gestational age was 22 weeks (range 16-27). An autopsy provided a final diagnosis in $15(88.2 \%)$ out of 17 cases. The causes are summarized in Table 1. In two cases, there was no detectable anomaly in the fetuses and the placental causes could not be excluded as placenta was not available for examination.

Cases terminated for increased risk for chromosomal abnormality include two cases of Down syndrome. One case presented with hydrops fetalis, cystic hygroma neck, common atrioventricular canal defect with persistent left superior vena cava, and hypoplasia of thymus. Other case showed nuchal edema, hydrocephalus, and abnormal left hand, feet, and legs. There was one case of Turner syndrome with partial deletion of short arm of $X$ chromosome. This case showed telangiectatic vascular nevi, hypoplastic nails, widely spaced nipples, clitoromegaly, septate vagina, and aortic arch isthmus hypoplasia. In one case, amniocentesis and FISH showed deletion of short arm of chromosome

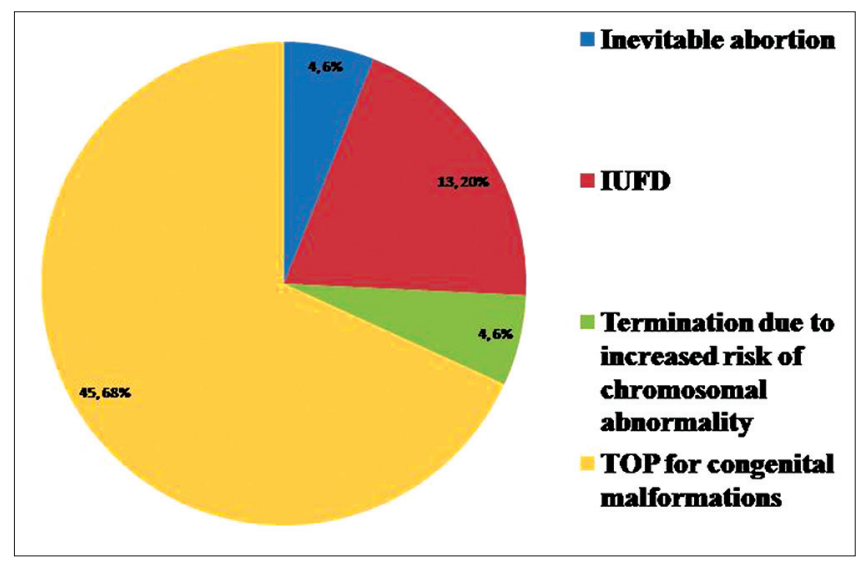

Figure 1: The pie diagram shows causes of fetal autopsies requested 
Table 1: Causes of intrauterine fetal death in the second trimester

\begin{tabular}{|c|c|}
\hline Causes & Number of cases $(n=17)$ \\
\hline 1. Placental causes & 10 \\
\hline Cord stricture & 6 \\
\hline $\begin{array}{l}\text { Hyper coiled cord with fetal vascular } \\
\text { obstruction }\end{array}$ & 1 \\
\hline Massive perivillous fibrin deposition & 1 \\
\hline Infectious villitis with hydrops fetalis & 1 \\
\hline $\begin{array}{l}\text { Isolated hydrocephalous with central } \\
\text { placenta previa in mother and cord } \\
\text { stricture (spontaneous abortion) }\end{array}$ & 1 \\
\hline 2. Fetal causes & 4 \\
\hline $\begin{array}{l}\text { Hypoplastic left heart syndrome with } \\
\text { visceral heterotaxy }\end{array}$ & 1 \\
\hline Healed myocardial infarction & 1 \\
\hline $\begin{array}{l}\text { Hydrops fetalis due to premature } \\
\text { ductus closure }\end{array}$ & 1 \\
\hline $\begin{array}{l}\text { Bladder outlet obstruction due to } \\
\text { distal urethral stenosis (spontaneous } \\
\text { abortion) }\end{array}$ & 1 \\
\hline \multicolumn{2}{|l|}{ 3. Maternal cause } \\
\hline Maternal thrombophilia & 1 \\
\hline 4. Diagnosis not possible & 2 \\
\hline
\end{tabular}

15. USG examination of fetus showed bilateral mild ventriculomegaly, hypoplastic cerebellum, increased nuchal pad thickness, postaxial polydactyly in both feet, and multiple anomalies. An autopsy confirmed the USG findings and in addition showed focal cerebellar dysplasia. Parental karyotyping was suggested to confirm Prader-Willi/Angelman syndrome.

In fetuses terminated for congenital anomalies, the mean maternal age was 24 years (range: 18-32). The mean gestational age at the time of diagnosis was 21 weeks (13-27). A majority of them showed multiple malformations which are summarized in Tables 2 and 3. Central nervous system (CNS) anomalies were the most common followed by genitourinary malformations. The frequently encountered CNS anomaly was Arnold-Chiari II malformation with myelomeningocele. Two cases of rhombencephalosynapsis characterized by fusion of cerebellar hemisphere with absent cerebellar vermis were seen. There were four cases of hydrops fetalis and the underlying cause was detected in all. In a case of DiGeorge syndrome (DGS), there was hypoplastic thymus in the cervical region which was not detected on ultrasound [Figure 3]. A case of sirenomelia showed single median lower limb. Fetogram revealed single femur, two tibias, and no fibula [Figure 4].

Prenatal USG examination was available in all fetuses terminated due to prenatally diagnosed anomalies. There were a total of 121 anomalies in 45 cases. About $50(41.3 \%)$ out of 121 anomalies were diagnosed only on autopsy. Three anomalies identified on USG were not confirmed on autopsy examination and includes two Dandy-Walker complex (DW) and aqueduct stenosis. One of the cases of DW complex showed additional findings on autopsy, and a diagnosis of Fryns syndrome was offered. Anomalies detected exclusively on autopsy examination include 13 (26\%) gastrointestinal (malrotation of intestine), 13 (26\%) genitourinary, $5(10 \%)$ cardiovascular, $5(10 \%)$ facial abnormality (cleft palate and micrognathia), four cases of CNS lesions, two cases each of polysplenia, skeletal abnormalities, and ductal plate malformation liver, and one case each of congenital diaphragmatic hernia, omphalocele, choanal atresia, microphthalmia, and nesidioblastosis.

Complete agreement between the USG findings and autopsy results were seen in 17 cases $(39.7 \%)$. An additional finding in autopsy was noted in $25(62.2 \%)$ out of 45 cases. In 15 cases $(34.8 \%)$, the additional findings on autopsy changed the initial ultrasound diagnosis [Table 4]. In nine out of 15 cases, the revision of diagnosis led to significant change in recurrence risk $(3 \%-25 \%)$ in subsequent pregnancy.

\section{Discussion}

With the advent of newer imaging techniques with higher resolution, the rate of autopsy is declining steadily. This is true even in cases of perinatal autopsies. ${ }^{[4]}$ Perinatal autopsy still remains the gold standard in detecting the cause of death in IUFD and confirming the anomalies detected on ultrasound. ${ }^{[1]}$ The present study focuses on second-trimester fetal autopsies and in reemphasizing its value in detecting congenital anomalies.

In the present study, major indication for second-trimester fetal autopsy was TOP for congenital anomalies. In cases of IUFD, fetal malformations were noted in $23.5 \%$ of cases, this is slightly higher as compared to the study done by Joó et al. where fetal malformation was seen in $13.05 \%$ in second-trimester miscarriages..$^{[5]}$ A study done by Peng et al. showed that $18.7 \%$ cases of IUFD were associated with umbilical cord stricture, hypercoiling or combination of both, most of these demises occurred in the second trimester. ${ }^{[6]}$ The current study showed cord stricture and hypercoiling as a cause of IUFD in $41.1 \%$ of cases, significantly high. This highlights the importance of examination of the placenta and umbilical cord in cases with absence of congenital anomalies.

In fetus with deletion in chromosome 15, there were multiple anomalies including cerebellar hypoplasia. Deletion in chromosome 15 is known for phenotypic heterogeneity, with well documented, diverse clinical syndromes. The best known of these are Prader-Willi syndrome and Angelman syndrome, both of which are not associated with generalized cerebellar hypoplasia 
Table 2: Postmortem diagnosis in fetuses terminated for congenital malformations (limited to 1 or 2 systems)

\begin{tabular}{l} 
Congenital anomalies \\
\hline 1. Central nervous system malformations \\
Arnold-Chiari malformation II with \\
meningomyelocele \\
Hydrocephalous with aqueduct stenosis \\
Rhombencephalosynapsis
\end{tabular}

Rhombencephalosynapsis

\section{Hydrocephalus}

Lumbar meningomyelocele

Mild ventriculomegaly

2. Urogenital malformations

AR polycystic kidney disease

Bladder outlet obstruction due to the posterior urethral valve

Persistent cloaca with persistent Mullerian duct syndrome

Persistent Mullerian duct syndrome

3. Cardiovascular system malformation

D-transposition of great arteries

Congenitally corrected transposition of great arteries

4. Respiratory system

Congenital high-airway obstruction syndrome

Alveolar capillary dysplasia with

misalignment of pulmonary veins

5. Congenital diaphragmatic hernia [Figure 2]

6. Talipes equinovarus

7. Hydrops fetalis

SUA $=$ Single umbilical artery, TEV $=$ Talipes equinovarus

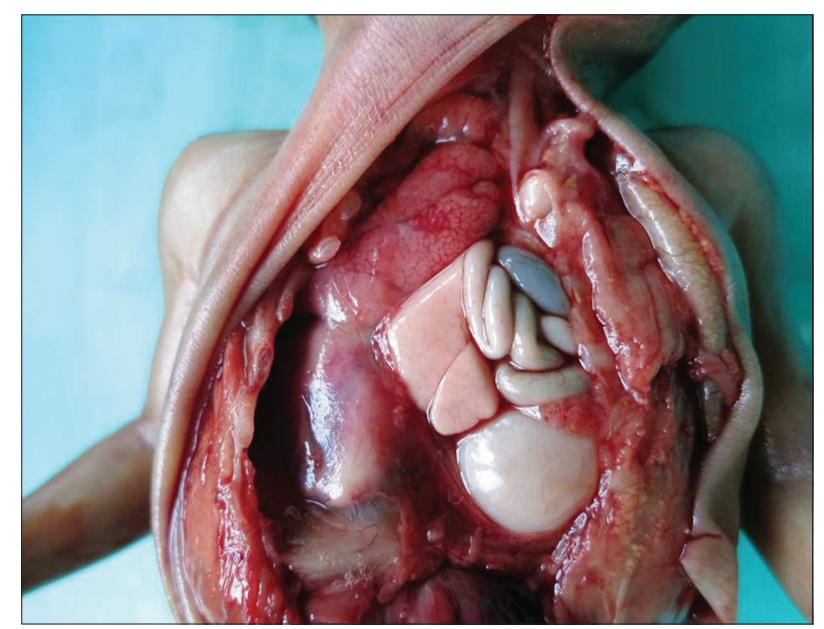

Figure 2: Congenital diaphragmatic hernia. The left hemithorax contains loops of small intestine and stomach pushing the heart and left lung to the right side

as seen in present case. To the best of our knowledge, this association has not been described in literature. It is possible that this might belong to the expanding spectrum of chromosome 15 q deletions. ${ }^{[7-9]}$

\begin{tabular}{l|l} 
Associated anomalies & Number of cases $(\boldsymbol{n}=\mathbf{2 7})$ \\
\hline & 9 \\
Agenesis of the right kidney and fused adrenals (1 case) & 3 \\
& 1 \\
Lobar holoprosencephaly, aqueductal stenosis, & 2 \\
interhemispheric cyst, TEV (1) & \\
Craniofacial dysmorphism (1) & 1 \\
Double aortic arch & 1 \\
Kyphoscoliosis spine, ruptured omphalocele & 1 \\
Hypoxic ischemic encephalopathy & 8 \\
$\begin{array}{l}\text { Ductal plate malformation } \\
\text { Hydrops fetalis (2 cases) }\end{array}$ & 2 \\
TEV (1 case) & 3 \\
Male pseudohermaphroditism (2), Occipital encephalocele, \\
TEV, agenesis right kidney, imperforate anus, and \\
malrotation intestine (1) \\
Ambiguous genitalia, male pseudohermaphroditism, \\
anorectal atresia, bladder outlet obstruction with bilateral \\
hydronephrosis, and renal obstructive dysplasia SUA
\end{tabular}

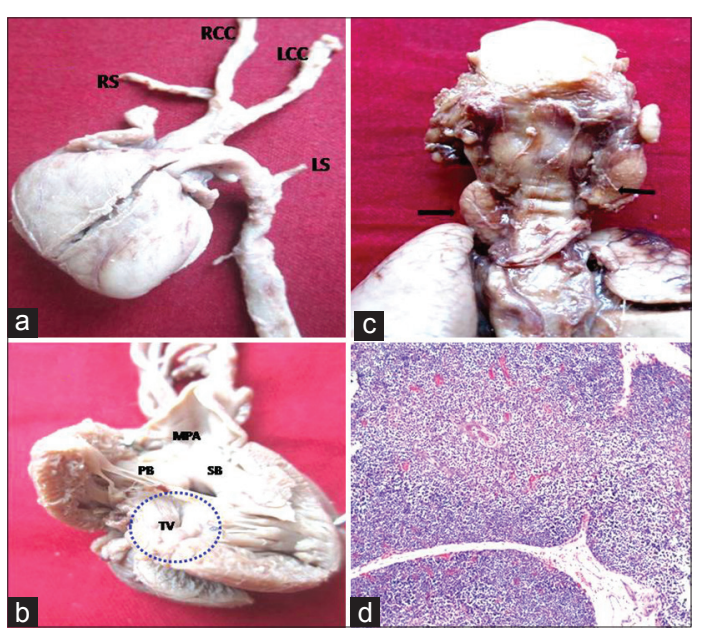

Figure 3: DiGeorge syndrome; (a) Interrupted aortic arch Type-B, (b) ventricular septal defect, perimembranous type, (c) cervical hypoplastic thymus, (d) lobules of thymic tissue composed cortex, medulla with Hassall's corpuscles ( $\mathrm{H}$ and E, $\times 100$ )

In 45 fetuses terminated for congenital anomalies, multiple malformations were seen in $75 \%$ of cases which is relatively high when compared to previous studies. ${ }^{[2,10]}$ 
CNS malformations were the most common followed by genitourinary anomalies. This is in concordance with the previous studies..$^{[2,9-12]}$ Arnold-Chiari malformation is characterized by downward displacement of cerebellum and brainstem into the spinal cord and is divided into three types. Type II is the most common form; this was true even in our series. ${ }^{[13]}$

Table 3: Postmortem diagnosis in fetuses terminated for congenital malformations (involving multisystem)

\begin{tabular}{lc}
\hline Diagnosis multiple malformations & $\begin{array}{c}\text { Number of } \\
\text { cases }(n=17)\end{array}$ \\
\hline 1. Syndromes/complexes/association & 13 \\
Fraser syndrome & 1 \\
Meckel-Gruber syndrome & 2 \\
Fryns syndrome & 1 \\
DiGeorge syndrome (SUA) & 1 \\
DiGeorge/velocardiofacial syndrome & 1 \\
Amniotic band syndrome & 1 \\
Charge syndrome & 1 \\
Zellweger syndrome/Smith-Lemli-Opitz syndrome & 1 \\
Sirenomelia with pseudo tail (SUA) & 1 \\
VACTERL or VATER Association (SUA) & 2 \\
Tuberous sclerosis complex & 1 \\
Multiple malformations - no definite syndrome & 4 \\
Renal hepatic pancreatic dysplasia with duodenal \\
atresia \\
$\begin{array}{l}\text { Situs inverses with polysplenia and conotruncal } \\
\text { malformation }\end{array}$ \\
$\begin{array}{l}\text { Meningocele, Arnold-Chiari malformation, } \\
\text { tricuspid atresia, and double-outlet right ventricle } \\
\text { Neural tube defect, Arnold-Chiari malformation, } \\
\text { hydrocephalus with aqueductal stenosis, agenesis } \\
\text { of corpus callosum, cerebellar hypoplasia, renal } \\
\text { dysplasia, malrotation of small intestine, and } \\
\text { polysplenia }\end{array}$ \\
\hline SUA = Single umbilical artery \\
\end{tabular}

SUA = Single umbilical artery

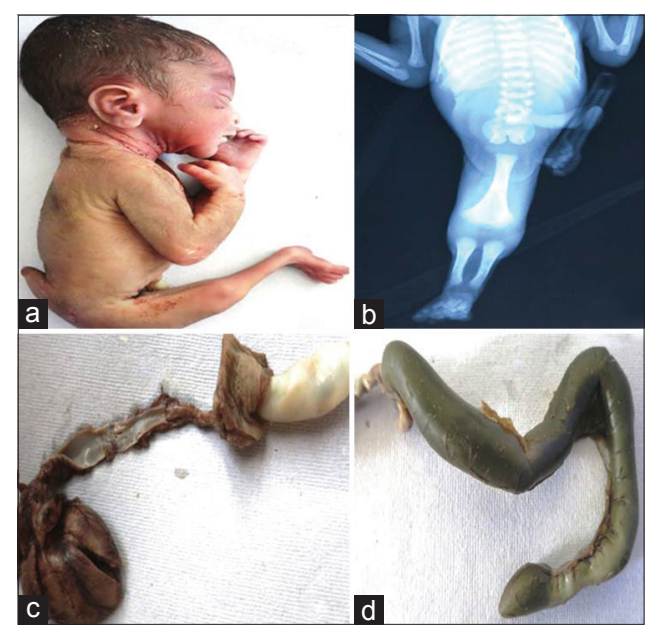

Figure 4: Mermaid fetus; (a) single median lower limb with pseudo tail in the lumbosacral region, (b) fetogram shows fused pelvic bones, single femur, and absent fibula, (c) hypoplastic descending abdominal aorta continuing as single umbilical artery, (d) meconium filled, blind-ended colon
DGS also known as del22q11.2 is the most common microdeletion. Phenotypic features include heart defects, thymic hypoplasia/agenesis, facial dysmorphism, and developmental delay. ${ }^{[14]}$ Two cases of DGS were diagnosed on prenatal ultrasound examination in view of congenital heart defects and absent thymus. Autopsy examination revealed hypoplastic cervical thymus in one case. Ectopic thymus was noted in 1\% of children in a study of 3236 children at autopsy, of these $71 \%$ had features of DGS. ${ }^{[15]}$ This might explain the variable immune status in the patients with DGS. Radiologist should be familiar with the locations of ectopic thymus and try to look for them when it is not found in the anterior mediastinum.

There was a case of sirenomelia with atypical skeletal framework. Sirenomelia is a rare CM characterized by varying degree of fusion of the lower limbs, single umbilical artery, and internal malformations related to genitourinary and gastrointestinal systems. ${ }^{[16]}$ Stocker and Heifetz have classified sirenomelia into seven types based on skeletal framework in the lower limbs. ${ }^{[17]}$ The bone pattern in the present case does not fit into any of the subtypes described in the literature. The exact etiological cause for sirenomelia remains unclear, but widely accepted hypothesis include defective blastogenesis and vascular steal hypothesis. ${ }^{[16]}$

In the present study, fetal autopsy provided definitive diagnosis in $95 \%$ of cases and confirmed ultrasound findings in $93 \%$ of cases, which is comparable to the previous studies. ${ }^{[2,12,18]}$ An autopsy could not confirm DW complex in two cases. The previous studies have shown a poor correlation between ultrasound and autopsy findings in cases of DW complex with concordance being achieved in 55\%, even after standardized reevaluation of sonographic and pathology images. ${ }^{[19]}$ The poor correlation could be attributed either due to the membranous quality of the cyst wall with loss of fluid during anatomical dissection or due to the overdiagnosis of DW complex on ultrasound. Hence, the diagnosis should be reserved to cases which show all the classical findings on ultrasound. In doubtful cases, repeat ultrasound or magnetic resonance imaging (MRI) should be suggested to confirm the diagnosis. ${ }^{[19]}$

On comparing autopsy and ultrasound findings, our study showed complete agreement in 37.7\% (17/45), partial agreement in $22.2 \%(10 / 45)$, and discordance in $33.3 \%(15 / 45)$. Thus, overall agreement was seen in $59.9 \%$. This is in concordance with study done by Yeo et al. ${ }^{[20]}$ Table 5 shows comparison of autopsy and ultrasound findings in various studies. ${ }^{[2,10,12,20,21]}$

Anomalies that were missed on USG examination were related to gastrointestinal, genitourinary, cardiovascular 
Table 4: Comparison of ultrasound findings with autopsy findings in cases of discrepancy

\begin{tabular}{ll}
$\begin{array}{l}\text { Serial } \\
\text { number }\end{array}$ & USG finding with diagnosis \\
\hline 1 & $\begin{array}{l}\text { Sacral meningomyelocele, bifid spine with the } \\
\text { hypoplastic right ventricle of the heart }\end{array}$ \\
2 & $\begin{array}{l}\text { Anhydramnios, B/L renal agenesis } \\
3\end{array}$ \\
$\begin{array}{l}\text { Anhydramnios, cystic dilatation of biliary radicles } \\
\text { and common bile duct, a cyst in pancreas, bilateral } \\
\text { multicystic dysplastic kidneys, microcephaly and } \\
\text { shot bowed tibia - Ivemark syndrome }\end{array}$
\end{tabular}

$4 \quad$ Situs ambiguous, isolated levocardia, VSD, and truncus arteriosus

$5 \quad$ Cerebellum V-shaped with large cisterna magna. ? partial agenesis of inferior cerebellar vermis- possibility of DW complex

6 Short femur, humerus, narrow chest- Possibly achondroplasia

Autopsy findings with diagnosis

Arnold-Chiari malformation and tricuspid atresia with double-outlet right ventricle

Cryptophthalmos, ventriculomegaly, bifid nasal tip, clitoromegaly, B/L renal agenesis, absent vagina, uterus, and proximal fallopian tubes - Fraser syndrome Bilateral cleft lip, cleft palate, lingual abnormalities and dysplastic

epiglottis. Occipital encephalocele, Arnold-Chiari malformation Type III. Holoprosencephaly. Diffuse cystic renal dysplasia congenital hepatic fibrosis (ductal plate malformation), choledochal cyst Todani Type IV. Persistent left SVC, mild atrioventricular valve dysplasia. Ambiguous external genitalia, bilateral testes. Postaxial polydactyly, bow legs Meckel-Gruber syndrome Situs inversus, isolated levocardia with polysplenia, and conotruncal malformation

$\mathrm{CDH}$, malrotation of the intestine, $\mathrm{B} / \mathrm{L}$ cleft palate, ankyloglossia, bifid tongue, and uterus didelphys-Fryns syndrome

Syndactyly, postaxial polydactyly of hands and feet, dysplasia of epiglottis, nonrotation of intestine, ductal plate malformation of liver, renal dysplasia, X-ray - B/L shortening of long bones of the upper and lower limbs - MeckelGruber syndrome-variant

7 Oligohydramnios, B/L echogenic kidneys to R/O CMV

$8 \quad$ Increased nuchal translucency, generalized subcutaneous edema, hypertelorism, midline facial cleft, small omphalocele, cardiac outflow tract anomaly. Suggested invasive test to rule out aneuploidy. Patient not willing for amniocentesis

9 Lumbosacral spina bifida and Arnold-Chiari malformation

AR PCKD with congenital hepatic fibrosis

Craniofacial defects with a membranous tag at the head - cranioschisis, absent ears, and nose, bilateral cleft lip and palate, Conotruncal cardiac anomaly? Transposition of great arteries with pulmonary atresia? Double outlet right ventricle with pulmonary atresia, abdominoschisis, renal cystic dysplasia - suggestive of amniotic band syndrome

Lumbar meningomyelocele, ruptured omphalocele

10 Bilateral presacral kidneys with bilateral hydronephrosis due to pelviureteric junction obstruction, parenchyma of left kidney is dysplastic

11 SUA, TOF, ectopic hydronephrotic left kidney, left clubfoot with absent 2 nd to 5 th digits

Ambiguous genitalia, male pseudohermaphroditism, persistent mullerian ducts Anorectal atresia, bladder outlet obstruction with bilateral hydronephrosis, and renal obstructive dysplasia. SUA

TOF with the right aortic arch and left-sided patent ductus arteriosus, atresia of distal sigmoid, rectum and anus, fused crossed renal ectopia with hydronephrosis, left clubfoot with a single digit

Fetogram-hemivertebra, absent metatarsal I bones-vacterl association

12 Pierre syndrome, left hydronephrosis due to pelviureteric obstruction

13 Two echogenic masses suggestive of cardiac rhabdomyoma

Bilateral posterior choanal atresia, lop ears, Micrognathia, Microphthalmia, persistent cloaca, left hydronephrosis - CHARGE syndrome

Heart: Multiple rhabdomyomas

Brain: Subependymal nodules of dystrophic neurons and astrocytes - tuberous sclerosis complex [Figure 5]

14 Complete AVSD

Bilateral cleft lip and palate, echogenic focus left ventricle

Congenitally corrected transposition of great arteries

Alveolar capillary dysplasia with misalignment of pulmonary veins, bilateral cleft lip and palate, mild pyloric stenosis, bladder outlet obstruction? Vascular dysplasia kidneys and brain

TOF = Tetralogy of Fallot, CDH = Congenital diaphragmatic hernia, SUA = Single umbilical artery, SVC = Superior vena cava, USG = Ultrasonography, $\mathrm{CMV}=$ Cytomegalovirus, $\mathrm{B} / \mathrm{L}=$ Bilateral, $\mathrm{DW}=$ Dandy-walker complex, $\mathrm{AVSD}=$ Atrio ventricular septal defect, $\mathrm{VSD}=$ Ventricular septal defect, $\mathrm{R} / \mathrm{O}=\mathrm{Rule}$ out, AR PCKD= Autosomal recessive polycystic kidney disease

systems, and facial defects. Antenatal detection of these CMs depends on the expertise of sonologist, quality of equipment, maternal habitus, and reduction in liquor volume. ${ }^{[22]}$ In addition, some cardiac, gastrointestinal, and renal abnormalities are not evident at 20 weeks. Few are histopathological diagnosis (e.g.: tuberous sclerosis, PCKD). Oligo- and anhydramnios were noted in some of our cases. All the above factors could explain the shortcomings of routine antenatal USG examination. Other prenatal diagnostic modalities such as three-dimensional ultrasound and MRI will provide better resolution for CNS and soft-tissue abnormalities. Detailed analysis of fetus using these advanced imaging modalities may help in achieving higher rates of complete agreement. Implementing them in routine antenatal screening may not be feasible due to higher cost, lack of expertise, and limited availability in developing countries.

When the parents are reluctant to give consent for full autopsy due to religious reasons, limited, or minimally invasive autopsy may be of value. Minimally 


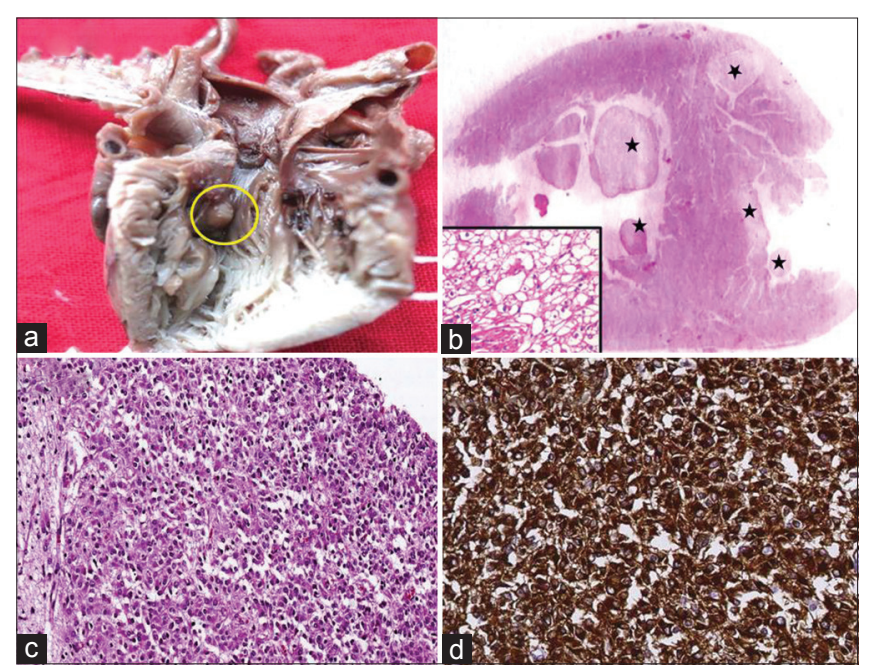

Figure 5: Tuberous sclerosis complex: (a) fleshy, pale brown mass in the left ventricular outflow tract, (b) transverse section of the heart shows multiple paler nodules $\left(^{*}\right)$ in subendocardial and intramural location. Inset shows high-power view of the nodule consisting of large vacuolated cells-rhabdomyoma ( $\mathrm{H}$ and $\mathrm{E}, \times 400)$, (c) section from medulla shows large subependymal plaque consisting of a cellular admixture of glial cells $(\mathrm{H}$ and $\mathrm{E}, \times 100)$ and $(\mathrm{d})$ these cells strongly express GFAP (IHC, x400)

Table 5: Comparison of autopsy and ultrasound findings in various studies

\begin{tabular}{|c|c|c|c|c|}
\hline \multirow[t]{2}{*}{ Studies } & \multirow{2}{*}{$\begin{array}{c}\text { Total } \\
\text { number } \\
\text { of cases }\end{array}$} & \multicolumn{2}{|c|}{$\begin{array}{c}\text { No change in initial USG } \\
\text { diagnosis }\end{array}$} & \multirow{2}{*}{$\begin{array}{l}\text { Change in } \\
\text { initial USG } \\
\text { diagnosis } \\
(\%)\end{array}$} \\
\hline & & $\begin{array}{c}\text { Complete } \\
\text { agreement (\%) }\end{array}$ & $\begin{array}{l}\text { Added to USG } \\
\text { findings (\%) }\end{array}$ & \\
\hline $\begin{array}{l}\text { Sankar and } \\
\text { Phadke }\end{array}$ & 134 & 41.0 & 58.0 & 1.49 \\
\hline Andola et al. ${ }^{[10]}$ & 39 & 50 & 29.54 & 9.09 \\
\hline $\begin{array}{l}\text { Vimercati et al. } \\
\text { [21] }\end{array}$ & 144 & 71 & 35 & 17 \\
\hline Yeo et al. ${ }^{[20]}$ & 88 & 65 & 35 & - \\
\hline Grover et al..[12] & 40 & 32.5 & 42.5 & 25.0 \\
\hline Present study & 45 & 37.7 & 22.2 & 33.3 \\
\hline
\end{tabular}

USG = Ultrasonography

invasive autopsy includes external examination with photography, placental examination, genetic analysis, and histopathological assessment of open or targeted biopsy of specific internal organs. Imaging studies, such as X-ray, postmortem MRI or micro-computed tomography, and assessment of body cavity fluids may be helpful to a certain extent.

Postmortem MRI can provide the details of structural malformation; however, it is not useful in cases of suspected infection, skeletal dysplasia, and in fetuses with severe maceration. It is not cost-effective and cannot provide details at histopathological levels.

Although minimally invasive autopsy can provide additional information in some cases, clinicians should explain to the concerned parents that complete perinatal autopsy remains the gold standard method for identifying the causes of fetal autopsy and its risk of recurrence.

\section{Conclusions}

The abnormalities detected by the fetal autopsy can be minor, major, or additional findings that modify the recurrence risk in subsequent pregnancy from 1\%-3\% to $25 \%$. Thus, autopsy plays an essential role in accurate diagnosis and appropriate genetic counselling. The present study reemphasizes the need for fetal autopsy even in the era of advanced imaging techniques

\section{Declaration of patient consent}

The authors certify that they have obtained all appropriate patient consent forms. In the form the patient(s) has / have given his/her/their consent for his/her/their images and other clinical information to be reported in the journal. The patients understand that their names and initials will not be published and due efforts will be made to conceal their identity, but anonymity cannot be guaranteed.

\section{Acknowledgment}

The authors express their profound gratitude to Dr. Ammu Sivaraman, emeritus professor, Department of Pathology, PSGIMSR, under whose guidance all the autopsies were meticulously performed.

\section{Financial support and sponsorship Nil.}

\section{Conflicts of interest}

There are no conflicts of interest.

\section{References}

1. Ernst LM. A pathologist's perspective on the perinatal autopsy. Semin Perinatol 2015;39:55-63.

2. Sankar VH, Phadke SR. Clinical utility of fetal autopsy and comparison with prenatal ultrasound findings. J Perinatol 2006;26:224-9.

3. The Royal College of Obstetricians and Gynaecologists and Royal College of Pathologists. Fetal and Perinatal Pathology: Report of a Joint Working Party. London: RCOG Press; 2001.

4. Boyd PA, Tondi F, Hicks NR, Chamberlain PF. Autopsy after termination of pregnancy for fetal anomaly: Retrospective cohort study. BMJ 2004;328:137.

5. Joó JG, Beke A, Berkes E, Papp Z, Rigó J Jr., Papp C, et al. Fetal pathology in second-trimester miscarriages. Fetal Diagn Ther 2009;25:186-91.

6. Peng HQ, Levitin-Smith M, Rochelson B, Kahn E. Umbilical cord stricture and overcoiling are common causes of fetal demise. Pediatr Dev Pathol 2006;9:14-9.

7. Cox DM, Butler MG. The 15q11.2 BP1-BP2 microdeletion syndrome: A review. Int J Mol Sci 2015;16:4068-82.

8. Sieg KG. Neurodevelopmental disorders associated with chromosome 15. Jefferson J Psychiatry 2011;8:9-23.

9. Hayashi M, Itoh M, Kabasawa Y, Hayashi H, Satoh J, Morimatsu Y, 
et al. A neuropathological study of a case of the Prader-Willi syndrome with an interstitial deletion of the proximal long arm of chromosome 15. Brain Dev 1992;14:58-62.

10. Andola US, Am A, Ahuja M, Andola SK. Congenital malformations in perinatal autopsies - A study of 100 cases. J Clin Diagn Res 2012;6:1726-30.

11. Akgun H, Basbug M, Ozgun MT, Canoz O, Tokat F, Murat N, et al. Correlation between prenatal ultrasound and fetal autopsy findings in fetal anomalies terminated in the second trimester. Prenat Diagn 2007;27:457-62.

12. Grover S, Garg B, Sood N, Arora K. Lethal congenital malformations in fetuses-antenatal ultrasound or perinatal autopsy. Fetal Pediatr Pathol 2017;36:220-31.

13. Nejadi MN, Zafarani F, Ahmadi F, Rashidi Z. Arnold-chiari type II malformation: A case report and review of prenatal sonographic findings. Iran J Fuzzy Syst 2008;11:179-82.

14. Besseau-Ayasse J, Violle-Poirsier C, Bazin A, Gruchy N, Moncla A, Girard F, et al. A French collaborative survey of 272 fetuses with 22q11.2 deletion: Ultrasound findings, fetal autopsies and pregnancy outcomes. Prenat Diagn 2014;34:424-30.

15. Bale PM, Sotelo-Avila C. Maldescent of the thymus: 34 necropsy and 10 surgical cases, including 7 thymuses medial to the mandible. Pediatr Pathol 1993;13:181-90.

16. Valenzano M, Paoletti R, Rossi A, Farinini D, Garlaschi G,
Fulcheri E, et al. Sirenomelia. Pathological features, antenatal ultrasonographic clues, and a review of current embryogenic theories. Hum Reprod Update 1999;5:82-6.

17. Stocker JT, Heifetz SA. Sirenomelia. A morphological study of 33 cases and review of the literature. Perspect Pediatr Pathol 1987;10:7-50.

18. Phadke SR, Gupta A. Comparison of prenatal ultrasound findings and autopsy findings in fetuses terminated after prenatal diagnosis of malformations: An experience of a clinical genetics center. J Clin Ultrasound 2010;38:244-9.

19. Phillips JJ, Mahony BS, Siebert JR, Lalani T, Fligner CL, Kapur RP, et al. Dandy-walker malformation complex: Correlation between ultrasonographic diagnosis and postmortem neuropathology. Obstet Gynecol 2006;107:685-93.

20. Yeo L, Guzman ER, Shen-Schwarz S, Walters C, Vintzileos AM. Value of a complete sonographic survey in detecting fetal abnormalities: Correlation with perinatal autopsy. J Ultrasound Med 2002;21:501-10.

21. Vimercati A, Grasso S, Abruzzese M, Chincoli A, de Gennaro A, Miccolis A, et al. Correlation between ultrasound diagnosis and autopsy findings of fetal malformations. J Prenat Med 2012;6:13-7.

22. Loughna P. Congenital abnormalities: Failure to detect and treat. Obstet Gynaecol 2008;10:33-7. 